\title{
CINCO GRAMÁTICAS CONTEMPORÂNEAS: LEITURA DE CONCEPÇÕES
}

Lia Abrantes Antunes Soares*

RESUMO: A área de estudos linguísticos conta com importantes obras de referência publicadas no Brasil. Neste estudo, selecionamos cinco gramáticas, a saber: Moderna Gramática Portuguesa, Gramática de Usos do Português, Gramática Houaiss da Língua Portuguesa, Nova Gramática do Português Brasileiro e Gramática da Língua Portuguesa Padrão, com o propósito de entender qual concepção de linguagem norteia a produção de cada obra e, assim, expor uma visão geral sobre o tema. Optamos por organizar este artigo em duas seções. Primeiro, analisamos a parte introdutória em que os autores estabelecem critérios para a elaboração textual, confrontando as informações sobre 0 planejamento das obras (posicionamento teórico, público-alvo, complexidade metalinguística). Em seguida, verificamos, com base na organização e no conteúdo descrito nas gramáticas, a abordagem assumida. Ao final da análise, encontramos concepções moderadas de interpretação continuísta e descontinuísta da tradicional descrição gramatical.

Palavras-chave: concepção de língua; abordagens do português; descrição gramatical

\section{Introdução}

Com o propósito de entender qual concepção de linguagem norteia a produção de gramáticas no Brasil e, assim, expor uma visão geral sobre o tema, elegemos, como objeto de investigação, cinco gramáticas, a saber: Moderna Gramática Portuguesa, Gramática de Usos do Português, Gramática Houaiss da Língua Portuguesa, Nova Gramática do Português Brasileiro, Gramática da Língua Portuguesa Padrão. Para alcançar nosso objetivo, dividimos este estudo em duas etapas. Na primeira, examinamos a parte introdutória das obras e, na segunda, a organização dos pontos tratados nas obras.

\footnotetext{
*Professora da Universidade Federal do Rio de Janeiro. E-mail: lia.soares@gmail.com
} 
A parte introdutória de uma obra oferece a seus leitores os caminhos escolhidos pelos autores, atinentes ao tratamento teórico e metodológico do objeto de estudo, como atitude transparente e comprometida com o fazer científico. Sendo assim, na primeira etapa de nossa análise, confrontamos informações encontradas no prefácio ou apresentação/introdução de cada gramática selecionada, com propósito de anunciar os aspectos que servem de parâmetro para análise (os títulos e a definição do público-alvo por exemplo), fazendo remissão à sequência do texto, a fim de guiar nossas observações sobre o robusto empreendimento de cada um dos autores, a despeito de qualquer fragilidade que nelas se possa apontar.

Partindo do título das obras, já se pode estabelecer marcas distintivas e orientadoras para concepção dos objetivos de cada autor no empreendimento de suas lições. Além da escolha, sempre reveladora, dos títulos, um ponto importante para a concepção de uma obra é a definição do público a quem se destina, diretamente relacionada à adequação da terminologia, explanação e exemplificação, a ser observada pelos autores. Cabe ainda identificar o posicionamento sobre a necessidade de renovação das tradicionais lições da Nomenclatura Gramatical Brasileira (NGB). O último ponto ainda observado na primeira etapa, diz respeito às duas fases relativas à elaboração textual: a de reconhecimento da realidade sóciohistórica e linguística do português brasileiro e a de apoio de especialistas para um trabalho em conjunto e de revisão crítica.

$\mathrm{Na}$ segunda etapa de análise, identificamos a concepção de gramática que norteia a organização dos capítulos de cada obra selecionada. Com o cumprimento das duas etapas de análise, chegamos a uma visão geral das gramáticas, em que a continuidade é alternada com uma descontinuidade aos achados da Gramática Tradicional.

\section{Visão geral das gramáticas}

\subsection{O que dizem os títulos?}

A escolha do adjetivo inicial no título da obra de Evanildo Bechara, Moderna Gramática Portuguesa (MGP), em sua $37^{\text {ạ }}$ edição ${ }^{1}$, revela a intenção progressista em relação aos modelos de gramática anteriores. Ao considerar resultados de pesquisas linguísticas, nacionais e internacionais, do século $\mathrm{XX}$, e tratar de aspectos não abordados pela Nomenclatura Gramatical Brasileira, Bechara demonstra alinhamento com a tendência de ampliação dos estudos descritivos para outras partes do sistema de expressão (fonologia, estilística, versificação e pontuação), coerente com a indicação de modernidade. A decisão de empreender, nas 37ạ (1999) e 38ª (2015) edições, atualização no plano teórico e na orientação normativa da teoria gramatical, com auxílio de críticas e sugestões enviadas por colegas, além de leituras de pesquisas atualizadas, harmoniza-se com a noção de modernidade.

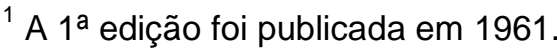


A menção ao termo "usos" no título da obra de Maria Helena de Moura Neves, Gramática de usos do português ${ }^{2}$ (GUP), indica o recorte teórico e metodológico que o leitor nela deve encontrar. Ao destacar os "usos", a autora indica que trata seu objeto por um viés descritivo e normativo, que inclui além da norma padrão, a "frouxidão" de certos usos característicos de um "registro distenso". Um exemplo de usos "frouxos" da língua é oferecido na descrição das construções causais, em que a autora inclui a locução por causa que, com exemplo retirado de Sagarana, de Guimarães Rosa: "Demorei a vir, mas foi POR CAUSA QUE não queria chegar aqui com as mãos abanando" (p.803). Logo abaixo do exemplo, Neves chama a atenção do leitor para o uso distenso da locução, embora não ofereça discussão a esse respeito.

A opção pela descrição dos usos linguísticos sinaliza ao consulente a heterogeneidade de variedades e de situações discursivas que compõem a atividade verbal. Apesar disso, como destaca Lima (2016), a indicação de que certos usos selecionados pela autora não são aleatórios, mas dependentes da comunidade de fala e da situação discursiva, poucas vezes é explicitada ao consulente, podendo ele fazer inferências a esse respeito, se for conhecedor da obra de onde o exemplo foi retirado. Caso contrário, perde a riqueza de informações abrigadas nas escolhas selecionadas pela autora.

Embora, em seu título, não haja indicação de que variedade do português a obra trata, a autora esclarece, logo no primeiro período da Apresentação, que a GUP "mostra como a língua portuguesa está sendo usada no Brasil" (p.13), marcando seu posicionamento quanto à distinção das variantes do português.

Ao contrário das obras anteriores, A Gramática Houaiss da Língua Portuguesa (GHLP), de José Carlos de Azeredo, com 1ํㅡㄹ edição em $2008^{3}$, não aponta, em seu título, para os pressupostos teóricos e metodológicos adotados na obra. No entanto, apesar de sua aparente neutralidade, ao carregar o nome do importante lexicógrafo Antônio Houaiss, entende-se que a obra não poderia ter sido encomendada a um estudioso comum a lavra que não coincidisse com os objetivos ligados à produção de obras de referência do Instituto Antônio Houaiss. A indicação da variedade do português a ser abordada, entretanto, encontra-se no início da Apresentação, na qual se informa que a obra trata do português padrão escrito no Brasil.

O título da obra de Ataliba T. de Castilho, Nova Gramática do Português Brasileiro (NGPB), em sua $1^{\text {a }}$ edição, publicada em $2010^{4}$, especifica o objeto de estudo - 'o português brasileiro', declarando ao leitor seu posicionamento quanto à realidade linguística do Brasil. Essa escolha está pautada em anos de dedicação a projetos de pesquisa que atestaram novos rumos tomados pela língua no país. $E$ como o próprio autor comenta na Introdução, a expressão serve para designar a identidade linguística de indivíduos de uma sociedade, como um certificado que autoriza a pesquisa científica da língua usada por brasileiros. Ainda reforça a decisão pelo português brasileiro a escolha das cores pátrias nas palavras que

\footnotetext{
${ }^{2}$ A 1aㅡ edição foi publicada em 1999 e, a 2ª , citada neste artigo, em 2011.

${ }^{3}$ Neste artigo citamos $3^{a}$ edição, publicada em 2013.

${ }^{4}$ Neste artigo citamos $2^{\underline{a}}$ reimpressão da $1^{\underline{a}}$ edição, publicada em 2012.
} 
compõem o título e a capa da obra, traduzindo a intenção do autor de legitimar a identidade do objeto de estudo.

Outro ponto a ser destacado em seu título diz respeito ao qualificador nova que o inicia. Além de apontar para a concretização de um novo projeto, dentre tantos outros sobre o português do Brasil (PB), diferencia-se do título da obra de Mario Perini, Gramática do Português Brasileiro, publicada em março de 2010.

Quanto à Gramática da Língua Portuguesa Padrão (GLPP), a mais recente das obras observadas neste estudo, surpreende pelo fôlego empreendido na elaboração do volume com 1343 páginas. Publicada em 2014, a gramática de Amini Boainain Hauy, ao se reportar à "língua padrão", indica o viés prescritivo que visa apontar as regras de uso da variedade de prestígio do português. O título limita o objeto de estudo a um só uso, mas não define a variedade relativa à "expressão da nacionalidade", o que reflete o posicionamento da autora sobre a "unificação linguística em toda a lusofonia" (p.34). No entanto, em certa medida, não deixa de apontar, em suas lições, observações sobre usos específicos da variedade brasileira.

\subsection{Público-alvo: adequação à profundidade da explanação e à exemplificação}

Inicialmente, identificamos o público para o qual as obras são indicadas e, em seguida, elegemos o aspecto morfológico para observação do modo de abordagem, na tentativa de verificar se a terminologia, a exemplificação e a explanação utilizadas em cada obra estão em consonância com o público a que a gramática visa atingir.

Dentre as cinco gramáticas, a única que não define seu público-alvo é a GLPP, embora dê a indicação de servir a fins didáticos. As outras são claras, como se observa, no quadro a seguir.

\begin{tabular}{|c|c|c|l|}
\hline \multicolumn{2}{|c|}{ OBRA } & AUTOR/ANO & \multicolumn{2}{|c|}{ PÚBLICO-ALVO } \\
\hline $\begin{array}{c}\text { Moderna } \\
\text { Gramática } \\
\text { Portuguesa }\end{array}$ & MGP & $\begin{array}{c}\text { BECHARA } \\
(2015)\end{array}$ & $\begin{array}{l}\text { professores, alunos e público } \\
\text { estudioso da língua portuguesa } \\
\text { (p.19); }\end{array}$ \\
\hline $\begin{array}{c}\text { Gramática de } \\
\text { usos do } \\
\text { português }\end{array}$ & GUP & $\begin{array}{c}\text { NEVES } \\
(2011)\end{array}$ & $\begin{array}{l}\text { falante comum que busca } \\
\text { orientação sobre os usos da língua } \\
\text { e estudioso da língua portuguesa } \\
\text { que investiga diferentes níveis de } \\
\text { análise (p.14); }\end{array}$ \\
\hline $\begin{array}{c}\text { Gramática } \\
\text { Houaiss da } \\
\text { Língua }\end{array}$ & GHLP & $\begin{array}{c}\text { AZEREDO } \\
(2013)\end{array}$ & $\begin{array}{l}\text { leitores médios, usuários da língua } \\
\text { portuguesa em geral, interessados }\end{array}$ \\
\hline
\end{tabular}




\begin{tabular}{|c|l|l|l|}
\hline Portuguesa & & na modalidade escrita padrão (p.27); \\
\hline $\begin{array}{c}\text { Nova Gramática } \\
\text { do Português } \\
\text { Brasileiro }\end{array}$ & NGPB & $\begin{array}{c}\text { CASTILHO } \\
(2012)\end{array}$ & $\begin{array}{l}\text { professores do ensino médio e } \\
\text { universitários da área de linguística, } \\
\text { alunos do curso superior e quem se } \\
\text { interessa pelas línguas naturais } \\
(p .33) ;\end{array}$ \\
\hline $\begin{array}{c}\text { Gramática da } \\
\text { Língua } \\
\begin{array}{c}\text { Portuguesa } \\
\text { Padrão }\end{array}\end{array}$ & GLPP & $\begin{array}{l}\text { HAUY } \\
(2014)\end{array}$ & Não há especificação. \\
\hline
\end{tabular}

Com exceção da NGPB, que delimita seus possíveis leitores, as outras três oferecem suas análises a um público muito abrangente. A fim de apontar evidências comprobatórias da não satisfação ao critério de adequação ao público-alvo, essencial à elaboração de obras de referência, buscamos dois pontos que poderiam ser alvo de interesse de um consulente não especializado. Um deles refere-se à abordagem de uma categoria mais básica de um sistema linguístico: o substantivo; o outro, a um aspecto morfossintático: o emprego da conjunção adversativa. Iniciemos pela definição de substantivo.

A tarefa do leitor comum, aquele que conhece a terminologia aplicada na educação básica, de localizar uma categoria para estudo nas gramáticas ora em estudo parece não exigir muito esforço no sumário da MGP, da GUP, da GHLP e da GLPP, ao contrário do que ocorre no sumário da NGPB, já que está abrigado em um item e subitem cuja terminologia, Sintagma nominal e Estatuto categorial do substantivo, que não é familiar ao usuário comum da língua, para quem a obra não é destinada.

Em se tratando do substantivo, a descrição empreendida para essa categoria em cada uma das gramáticas é exposta por meio de metalinguagem especializada, com incompatibilidade, em maior ou menor grau, de familiaridade a questões linguísticas, que se espera de um usuário comum, ainda que seja leitor médio do português. $O$ quadro a seguir traz definições retiradas das três obras indicadas a usuários da língua, em geral.

\begin{tabular}{|l|l|}
\hline OBRA & \multicolumn{2}{|c|}{ DEFINIÇÃO DE SUBSTANTIVO } \\
\hline & $\begin{array}{l}\text { "Substantivo - é a classe de lexema5 que se caracteriza por } \\
\text { significar o que convencionalmente chamamos objetos } \\
\text { substantivos, isto é, em primeiro lugar, substâncias (homem, casa, }\end{array}$ \\
\hline
\end{tabular}

${ }^{5}$ Grifo nosso. 


\begin{tabular}{|c|c|}
\hline MGP & $\begin{array}{l}\text { "(...) consiste, nas línguas flexivas como o português, em geral, } \\
\text { na combinação de um signo lexical, expresso pelo radical com } \\
\text { signos morfológicos expressos por desinências e alternâncias } \\
(\ldots)^{\prime \prime} \text { (p.117) }\end{array}$ \\
\hline GUP & $\begin{array}{l}\text { "Os substantivos são usados para referir-se às diferentes } \\
\text { entidades (coisas, pessoas, fatos etc.) denominando-as". (p.67) } \\
\text { "Cada substantivo comum tem, em primeiro lugar, um significado } \\
\text { lexical, decorrente de seu estatuto categorial, estatuto definido } \\
\text { basicamente pelas funções de denominação e de descrição da } \\
\text { classe de referentes". (p.67) } \\
\text { "1.2.2.2. Denominação } \\
\text { É com base nessa característica que a gramática tradicional } \\
\text { assenta sua definição de substantivo como "a palavra que } \\
\text { designa ou nomeia os seres. De fato, considerados } \\
\text { independentemente de sua ocorrência no enunciado, os } \\
\text { substantivos são nomes (designações de entidades cognitivas } \\
\text { e/ou culturais (como homem, livro, inteligência) que possuem } \\
\text { certas propriedades categorizadas no mundo extralinguístico". } \\
\text { (p.68) }\end{array}$ \\
\hline GHLP & $\begin{array}{l}\text { "A classe do substantivo reúne as seguintes características } \\
\text { principais: } \\
\text { a) dá nome às parcelas de nosso conhecimento representadas } \\
\text { como seres; } \\
\text { b) serve de núcleo às expressões referenciais do texto; } \\
\text { c) tem gênero próprio (masculino e feminino) e varia em número }\end{array}$ \\
\hline
\end{tabular}

${ }^{6}$ Grifo nosso.

${ }^{7}$ Grifos da autora. 
(singular ou plural);

d) desempenha as funções sintáticas de sujeito e de objeto direto". (p.155)

$\mathrm{Na}$ primeira definição proposta por Bechara, embora o termo destacado (lexema) possa causar dificuldade de compreensão ao consulente comum, os exemplos denotam claramente o que são objetos ou substâncias. Entretanto, na descrição relativa à estrutura interna do substantivo, o autor lança mão de termos como línguas flexivas, signo lexical e signos morfológicos, que compõem uma exposição bastante técnica, sem clarificação com exemplos que a ilustrem.

A GUP oferece descrição gradual e detalhada, em um percurso que expõe propriedades formais e funcionais da categoria. Neves inicia a abordagem do substantivo a partir de uma definição com enfoque no uso, bastante acessível ao leitor não especializado. Após a exemplificação para ilustrar tal definição, o nível de complexidade da descrição aumenta, em grande parte devido à terminologia utilizada (estatuto categorial), o que torna a lição menos acessível ao usuário comum.

Por outro lado, ao tratar da natureza dos substantivos comuns, no tópico 1.2.2.2. Denominação, é possível observar a preocupação da autora com uma exposição que retoma a visão tradicional do substantivo para, em seguida, aprofundar sua explanação a um nível mais abstrato, em que evoca entidades cognitivas e/ou culturais e categorização de propriedades extralinguísticas.

Ao identificar a categoria substantivo na GHLP, o consulente encontra uma descrição das características relativas à forma e à função. Entendemos que a definição seria mais acessível ao leitor médio, se a cada característica fosse inserido um exemplo. Os tópicos seguintes à definição citada no quadro tratam da classificação dos substantivos (Substantivos concretos e abstratos; Substantivos comuns e próprios; etc.) É importante destacar que Azeredo retoma o tratamento do substantivo no capítulo intitulado O sintagma nominal. Entretanto, um leitor médio, não especializado, não identificaria tal terminologia no sumário, como um ponto que aborda o emprego do substantivo.

Tanto a MGP quanto a GUP e a GHLP empregam terminologia especializada à descrição, de difícil alcance por usuários da língua em geral. Se por um lado definições simples, com terminologia simples, podem não contemplar todas as características de fenômeno se categorias linguísticas, por outro, a exemplificação clara e em número suficiente auxilia os leitores na compreensão. A questão não é relativa à qualidade das descrições, mas a quem são direcionadas. Entendemos haver um ponto de desequilíbrio entre o objetivo de alcançar um público-alvo muito abrangente e a profundidade empreendida na descrição dos fenômenos linguísticos, com uso de metalinguagem especializada. 
A GLPP não define seu público-alvo, apesar disso, vale incluí-la na discussão, em razão da declaração de Hauy de que o objetivo da obra seja didático (p.34), portanto, acessível ao consulente comum. Embora o conceito de substantivo englobe instituições, ações, estados, etc., como seres, a sua definição é simples e direta: "Substantivo é a palavra variável em gênero, número e grau, que nomeia seres em geral: pessoas, coisas, animais, vegetais, instituições, ações, estados, acontecimentos, fenômenos etc." (p.545).

No entanto, a exemplificação para substantivo, toda sob forma de enálage, é composta por textos poéticos, entre eles os de Fernando Pessoa:

Mas foi qualquer coisa de grande como o haver Deus.

Que o meu ouvir o teu silêncio não seja nuvens que atristem O teu sorriso...

Entre a árvore e o vê-la/ Onde está o sonho $?^{8}(p .545)$

Se o objetivo de oferecer exemplos contextualizados, e não de palavras soltas, é atingido pela autora, o de acesso aos sentidos dos textos, por um usuário comum da língua, pode ser comprometido pelos textos produzidos com intenção estética, e, portanto, afetando o propósito didático da obra.

Ainda a respeito da adequação da abordagem ao público destinado, destacamos o segundo ponto, relativo a um aspecto morfossintático, corroborando a visão de que é necessário um direcionamento mais específico em relação à definição, terminologia e exemplificação utilizadas, a fim de que se possa incluir o falante comum como consulente da obra. Tomamos o exemplo de Azeredo, ao considerar somente a conjunção mas como adversativa. O autor explica ao leitor que as outras palavras (porém, contudo, entretanto, todavia, no entanto) aprendidas, na escola, como conjunções coordenadas adversativas, são descritas na GHLP como advérbios ou adjuntos conjuntivos.

Bechara justifica seu posicionamento, explicando que, apesar de semelhante identidade semântica, as outras palavras tratadas como unidades adverbiais não têm função de conector. Entretanto, na MGP, além de mas, encontramos como conjunções adversativas porém - apesar de poder se deslocar livremente pela sentença (cf. PERINI, 1995) - e senão (marca de incompatibilidade).

Na NGPB, o consulente encontra descrição mais detalhada. Castilho adverte o leitor de que não há consenso quanto ao fato de as propriedades de mas serem as mesmas dessas cinco palavras classificadas como advérbios. Os exemplos a seguir mostram que mas poderia ocorrer somente em (a).

\footnotetext{
${ }^{8}$ Grifos da autora.
} 
a) Titia adormeceu; porém vovó continuou a cantar.

b) Titia adormeceu; vovó, porém, continuou a cantar.

c) Titia adormeceu; vovó continuou, porém, a cantar.

d) Titia adormeceu; vovó continuou a cantar, porém. (p.354)

Alinhada à visão tradicional, priorizando o critério semântico ao sintático, a GLPP apresenta todas essas palavras como conjunções adversativas. Hauy explica, em nota de rodapé (p. 806), que, antigamente, contudo, entretanto, todavia e no entanto eram classificadas como advérbios de concessão ou conjunções adverbiais, sem mencionar que classificações semelhantes a estas também são praticada por autores contemporâneos.

Nas quinze páginas da GUP em que construções adversativas introduzidas pelo mas são descritas detalhadamente, não há qualquer indicação de onde encontrar as outras palavras que, tradicionalmente, são apresentadas entre as conjunções adversativas. Como Neves também inclui o falante comum como leitor (p.13 e 14), indicar-Ihe, ainda no tópico Construções adversativas, em qual parte da gramática, porém, contudo, entretanto, todavia, no entanto, são apresentadas, seria um direcionamento importante. O mesmo acontece com as conjunções coordenativas conclusivas (portanto, por conseguinte, então).

A decisão de não inserir nota esclarecedora nos tópicos em que a tradição gramatical as formalizou não se harmoniza com a preocupação da autora em organizar sua obra a partir das classes gramaticais, a fim de facilitar a consulta de um leitor não especialista. Supomos que um consulente comum da língua não buscaria tais palavras junto à categoria dos advérbios. No entanto, a autora apresenta uma nota que faz referência ao tratamento tradicional dessas palavras, ao fim da apresentação das Subclasses dos advérbios. Uma adequação à localização de notas de esclarecimento quanto à abordagem não tradicional das construções adversativas alertaria o leitor médio para o tratamento diferenciado das categorias, proposto na GUP.

Para um leitor iniciante na área de estudos linguísticos e que pode contar com a GUP para aprofundar seus conhecimentos e entender as razões da organização das categorias ali tratadas, indicamos que antes da consulta ao ponto de interesse, leia os textos introdutórios de cada parte da obra, em que o assunto está alocado. Dessa forma, terá indicações da autora sobre possível abordagem descontinuísta à tradicional. No caso da busca pelas construções adversativas, o leitor já teria uma indicação de onde encontrar as outras palavras de significado semelhante a mas na Introdução da Parte IV - A junção -, em que a autora adverte que elementos como todavia e no entanto se distinguem de mas, pois "constituem em si mesmos, satélites adverbiais" (p.602).

Convém, pois, que as obras aqui analisadas sejam indicadas a estudiosos da área e não a usuários do português em geral. Caso contrário, destacamos a necessidade de adequação ao modo de exposição dos textos que compõem as definições, descrições e exemplos, dos fenômenos linguísticos e à remissão de assuntos tratados de forma não tradicional, quando o leitor comum é contemplado. 
Esclarecemos que de modo algum reivindicamos uma abordagem idêntica às das gramáticas pedagógica, mas, sim, que o leitor comum seja advertido sempre que haja tratamento diferenciado dos fenômenos linguísticos.

Independente de uma descrição mais ou menos técnica e aprofundada dos fatos gramaticais, em geral, percebemos uma preocupação dos autores em fazer correspondência entre a terminologia assumida e a terminologia tradicional. Essa correspondência revela também o status de língua protocolar com que a gramática tradicional é usada, "isto é, como uma língua 'neutra' que serve para apresentar os dados de forma 'objetiva', não teórica”, como afirma Borges Neto (2012, p.96).

Quanto às estratégias textuais, Bechara, Neves e Hauy assumem uma escrita mais expositiva e neutra. Azeredo e Castilho propõem uma composição entre exposição neutra e interativa, que proporciona ao leitor iniciado uma leitura fluida, sem alterar a profundidade com que os assuntos são tratados.

Chama atenção a estratégia de exposição dialógica de Castilho, declarada em sua apresentação: "Na exposição, falo eu, interpretando os achados da ciência atual. Nas indagações, falam os leitores, por meio de perguntas que imagino que eles estejam formulando." (p.32). O autor assume uma postura atenta a possíveis dúvidas e questionamentos de seus leitores, dirigindo-se a ele, muitas vezes, utilizando metáforas, como mostra o trecho a seguir.

Você poderá achar estranho identificar relações gramaticais entre morfemas de um lado e funções sintáticas de outro. Mas observe que a morfologia não é inimiga da sintaxe, e mesmo muita gente prefere casá-las para sempre, sob denominação de morfossintaxe. Estruturas lexicais e estruturas sintáticas são manifestações diferentes do mesmo impulso criativo. Frequentemente divorciamos os dois só para descrevê-los mais sossegadamente. Feito isso, anulamos o divórcio e restabelecemos a paz conjugal. (p.459)

Na GHLP, também observamos estratégias de aproximação do leitor durante a exposição. Por vezes o autor, ao selecionar a primeira pessoa do plural, chama o leitor à reflexão sobre um assunto, conferindo ao texto uma situação de interação. Lança mão ainda do modo imperativo, em que o leitor é convocado mais diretamente, como mostram os exemplos a seguir:

Suponhamos que uma dessas frases seja $A$ avó de Joãozinho parecia feliz quando ele a visitou. Sua representação escrita nos revela dez unidades independentes (palavras gráficas). (p.125) 
Sobraram as palavras 'o' e 'os', que nada significam no mundo das designações. Independentemente, porém, da diferença entre estas duas espécies, cada uma dessas palavras reúne um conjunto de informações:

a) Em empurre há, além do significado mesmo do verbo (compare-o com abra, afaste, encoste, que significam outras ações), as noções de ordem (compare com empurro, que expressaria uma mera declaração) (p.59)

Os recursos linguísticos escolhidos pelos dois autores, também usados por Perini (2010), é um forte atrativo, na medida em que o leitor, principalmente o estudante do curso de Letras, sente-se atendido ao iniciar sua caminhada acadêmica, reconhecendo no texto tanto a sua voz quanto a do autor. Vemos que a intenção de alcançar o leitor com uma abordagem clara e dialógica não diminui a qualidade e o valor da obra, nem o arcabouço intelectual dos autores, mas é apenas uma questão de estilo.

\subsection{Sobre a terminologia: tradição e renovação}

Não há dúvida que a Nomenclatura Gramatical Brasileira (NGB) trouxe, a partir de 1959, alguma estabilidade à, até então, caótica teoria gramatical, como atestam vários estudiosos. Entretanto, em se tratando de língua como um sistema complexo ${ }^{9}$, sempre surgirão novos fenômenos para desestabilizar o que se pensou estar estável por algum tempo. E para assegurar propostas de conceituação dos fatos gramaticais, mais adequadas às necessidades impostas pelo funcionamento da língua, é que a linguística, como ciência, disponibiliza novas interpretações dos fenômenos linguísticos para uma inevitável revisão.

A preocupação da NGB em escolher termos que dessem conta de tantos critérios para explicar fatos linguísticos resultou em questionamentos sobre a clareza e objetividade das escolhas. Concordamos com Hauy, quando argumenta que o desenvolvimento de variadas técnicas de descrição linguística que os estudos da linguagem proporcionam justifica a necessidade de terminologia para evitar divergências conceituais, no âmbito escolar (HENRIQUES, 2009).

Todas as cinco gramáticas parecem concordar com a necessidade de renovação das tradicionais lições da NGB. Bechara oferece "uma proposta de melhoria da vigente nomenclatura gramatical em nossos compêndios escolares" (p.20); Neves oferece ricas interpretações para os itens da língua organizados em classes definidas pela tradição gramatical, mas deixa claro que "não é propósito da obra trazer uma proposta de classificação" (p. 15); Azeredo propõe um "equilíbrio entre tradição e renovação [...] nos conceitos teóricos e descritivos' (p.26); Castilho

\footnotetext{
${ }^{9}$ A Teoria dos Sistemas Adaptativos e Complexos, desenvolvida para explicar sistemas naturais, como os meteorológicos, se mostrou adequada para tratar da linguagem por sua natureza dinâmica, processual, parcialmente imprevisível e complexa.
} 
se afasta das lições que listam "classificações, em que não se vê a língua, mas uma gramática" e apresenta o que há "por trás das classificações, identificando os processos criativos do português brasileiro que conduziram aos produtos listados" (p. 31).

Das cinco obras, somente a GLPP foi motivada especificamente pela intenção de propor um padrão gramatical que revisasse a NGB. Hauy pautou seu percurso de mais de vinte anos em um estudo crítico da gramática do português, "visando à elaboração de uma gramática-padrão para fins didáticos, alicerçada na coerência e uniformização dos conceitos e numa atitude científica de análise" (p.37).

Fato é que "aula de português implica o emprego de termos específicos para quem estuda uma língua" (HENRIQUES, 2009, p.21), assim como aula de qualquer outra disciplina. No entanto, é preciso, antes de qualquer coisa, assumir uma postura científica para o estudo de línguas. Como argumenta Perini (2010), não é possível estudar nenhuma disciplina sem dominar conceitos básicos, e o estudo da gramática, como parte fundamental de uma língua, requer apropriação desses conceitos condutores de uma visão da estrutura e funcionamento das línguas.

\subsection{Etapas para elaboração textual}

O último ponto da primeira etapa de análise diz respeito ao cumprimento de fases de elaboração textual. Conforme destaca Anjos (2016), a elaboração de gramáticas normativas deve passar por algumas fases, dentre as quais destacamos duas: (1) a de reconhecimento da realidade sócio-histórica e linguística do português brasileiro e (2) a de apoio de especialistas em diferentes componentes do sistema linguístico para um trabalho em conjunto e de revisão crítica.

O cumprimento da primeira fase é assumido por Neves, Azeredo e Castilho quando declaram, na parte introdutória das obras, que elegem o PB como objeto de estudo. Castilho ainda é mais específico ao dedicar seções sobre políticas linguísticas referentes ao ensino do PB como L1 (primeira língua) e L2 (segunda língua), história social e diversidade do PB.

Dentre as três gramáticas, destacamos a GUP, que descreve detalhadamente as várias possibilidades reais de usos, colhidas em um amplo corpus do PB escrito, composto por textos de literatura romanesca, dramática, técnica e jornalística.Tomamos como exemplo da descrição da realidade linguística a variação regional no tratamento do artigo definido e o registro no tratamento do advérbio (descrito em 104 páginas!). Neves usa o recurso \#, após uma explicação, para sinalizar usos diversos, como se observa a seguir.

a) Nomes de pessoas conhecidas ou famosas (especialmente no registro coloquial)

A Neusa Sueli sabe como eu sou. (NC) [...]

\# Esse uso do artigo é, entretanto, ligado a costume regional, familiar ou pessoal. Desse modo, também é comum que o artigo definido não seja usado: 
Achei $\varnothing$ Elvira meio esquisita. (VN) (p. 404)

2.1 De um ponto de vista morfológico, o advérbio é uma palavra invariável:

Entram Fernando e Vanessa de mãos dadas e MUITO contentes. (DEL) [...]

\# Encontram-se, entretanto, casos restritos de advérbio flexionado em gênero e número. Esses usos, que se referem a quantificadores, pertencem a um registro mais distenso e são considerados erros pela gramática normativa: (p.234)

É que ela é MEIA doente, já não tem vontade. (EM)

Sobre a segunda fase, todas as obras analisadas declaram o relevante trabalho coletivo, ou em relação à leitura crítica de especialistas (MGP, GUP, GHLP), ou à redação em parceria (GHLP), ou às referencias teóricas (MGP, GUP, GHLP, NGPB, GLPP), pois "línguas são tão complexas, que é impossível trabalhar solitariamente em sua análise", justifica Castilho (2010, p.32).

Para ilustrar a relevância da segunda fase, observamos procedimento usado por Hauy. Ao tratar dos pronomes, a autora comenta sobre o uso não rigoroso dos demonstrativos esse e este na variedade brasileira (p. 695), e já no prefácio, declara articulação de "valiosas citações de consagrados especialistas" (p. 33) que reconhecem não haver rigorosidade quanto à relação espacial que diferencia a escolha de uma forma ou outra, nem na escrita nem na fala. Para Bechara, um dos autores citados por Hauy, "Estas expressões não se separam por linhas rigorosas de demarcação; por isso exemplos há de bons escritores que contrariam os princípios aqui examinados e não faltam mesmo certas orientações momentâneas que fogem às perscrutações do gramático" (MGP, p.188).

\section{Organização das obras: visões de gramática}

Ao compactarem o complexo objeto de estudo, referente a domínios da língua portuguesa, nos limites de um livro, seus autores elegem uma visão de gramática e definem alguns critérios para execução do plano textual e para divisão em partes ou capítulos. A escolha por uma visão de gramática pressupõe um processo de construção empreendido durante a trajetória acadêmica dos estudiosos, portanto, não é definida apenas para elaboração de uma obra. Essa escolha diz respeito aos conceitos de língua e linguagem, que refletem na visão de gramática adotada, conferindo ao autor uma marca que será encontrada em suas lições. Dessa forma, identificamos a concepção de gramática que norteia a organização dos capítulos de cada obra selecionada.

Apesar de alguma semelhança entre a MGP, a GLPP e a GUP - são descritivas e normativas, organizadas a partir das tradicionais classes de palavras -, as duas primeiras incluem, além das divisões sugeridas pela NGB (fonética, 
morfologia e sintaxe), breve histórico sobre o português, conceitos envolvidos na teoria gramatical e estudo sobre fonologia. Nesse sentido, observamos continuidade e descontinuidade das lições tradicionais.

A GUP distribui as classes de palavras em grupos maiores relacionados aos processos organizadores do enunciado: predicação, referenciação, quantificação e indefinição, junção. Dessa forma, Neves contempla a descrição das propriedades formais e funcionais de itens lexicais e gramaticais nos níveis do sintagma, da oração e do enunciado, "isso significa que a interpretação das categorias linguísticas não pode prescindir da investigação de seu comportamento na unidade maior - 0 texto" (p. 15). Para a autora, é no uso em variadas instâncias que os itens da língua assumem sentido e definem função. Nessas bases de análise, ela deixa clara a concepção funcionalista de língua em uso de que a gramática é um componente.

Não se observa concepção semelhante na MGP nem na GLPP. Essas duas adotam uma visão de gramática como sistematização dos fatos da língua, "que alia a preocupação de uma científica descrição sincrônica a uma visão sadia da gramática normativa" (MGP, p. 20). A concepção de linguagem como "um sistema convencional de signos que objetiva a comunicação entre indivíduos, ou seja, construção e decodificação de mensagens" (GLPP, p.57) é partilhada pelos autores. Desse ponto de vista, o modo de construção do objeto de descrição reflete a concepção de gramática como o lugar das regularidades da língua para o bom uso em sociedade.

$\mathrm{Na}$ GHLP, Azeredo, em sua exposição clara e compatível com leitores iniciados, expõe princípios básicos norteadores da concepção de linguagem, como "traço singular da espécie humana" (p. 25) que tem o papel (i) de organizar o conhecimento adquirido com experiências do mundo, (ii) de codificá-lo em enunciados e (iii) de proporcionar interação em sociedade. $O$ autor entende gramática não como "uma armadura que enrijece a frase, mas um sistema de meios que torna possíveis a elaboração e a troca de significados por meio de uma língua" (p. 127).

Com a decisão de incluir logo na segunda parte, das oito que compõe a obra, um espaço dedicado à explicação teórica sobre linguagem e seu funcionamento, a GHLP demonstra a essencialidade do tema para uma abrangente educação linguística. Por um viés cognitivista e com exemplos que ilustram concretamente suas lições, Azeredo oferece a seus leitores descrição que parte do texto para que se observe que "a atribuição e a troca de significados são o fundamento da vida em sociedade" (p. 39) e para tais atividades é preciso usar a gramática da língua.

A gramática, como um suporte sólido para linguagem, também é descrita a partir de conceitos estruturalistas, utilizando a descrição formal mediante uma terminologia tradicional. Azeredo não ignora a necessidade de um tratamento equilibrado entre "tradição e renovação" para as propostas teóricas e descritivas na produção da GHLP. Nesse sentido, entendemos que utilizar-se da tradição é apenas um meio prático, operacional e neutro, isto é, uma forma protocolar (BORGES NETO, 2012) de identificar fenômenos linguísticos. 
Descritiva como as quatro obras citadas anteriormente, a NGPB delas se diferencia em alguns aspectos, dentre os quais apontamos a seleção dos assuntos que não segue as divisões tradicionais nem a terminologia sugerida pela NGB e, o mais distintivo, aquele que se refere à modalidade oral do PB. Apesar de os títulos e subtítulos de seus capítulos apresentarem terminologia técnica (exemplos: 11. Sintagma nominal; 11.4.2. Sintagmas nominais nucleados por pronomes neutros), o autor procura fazer em seu texto a correspondência com a terminologia tradicional ou protocolar, como se observa no exemplo a seguir:

Como vimos o substantivo tem por propriedade básica referenciar, desempenhando um papel importante no texto.

Em nossa tradição gramatical e linguística, o termo referência se especializou para indicar "designação, denominação" de seres e coisas, especializando-se o termo anáfora (ou, mais amplamente, foricidade) na indicação dos processos linguísticos de retomada do que já foi dito" (p. 469).

O exemplo acima mostra que a abordagem do substantivo vai além do nível do sintagma e da sentença, chegando ao nível do texto. As diferentes dimensões de análise contempladas por Castilho refletem sua concepção de linguagem como um conjunto de operações cognitivas realizadas na mente humana, possibilitando a competência comunicativa dos indivíduos. Essa concepção, fundamentada na sua teoria Multissistêmica de cunho funcionalista-cognitivista, se aproxima daquelas de Neves e Azeredo, pois consideram a gramática como parte de um sistema dinâmico, ativada com o uso da língua.

Na perspectiva multissistêmica que caracteriza a proposta teórica de Castilho, a gramática com seus componentes (sintaxe, fonologia e morfologia) é um dos quatro sistemas dinâmicos (léxico, gramática, semântica e discurso) acionados durante a complexa atividade linguística. $O$ autor rejeita a noção de hierarquia $e$ linearidade no funcionamento dos sistemas, ou seja, não há dependência, mas sim, interação entre eles e um componente central na língua, chamado dispositivo sociocognitivo. Para ele, a gramática se configura em um sistema de estruturas sintáticas, fonológicas e morfológicas que não são autônomas, mas "flexíveis e permeáveis às pressões do uso", sem serem "totalmente arbitrárias" e "sujeitas a reelaborações constantes" ( $p .73)$.

Embora Castilho se sirva de teorias modernas para estudo do PB, configurando descontinuidade em relação à $\mathrm{GT}$, admite "acrescentar um elo a mais na longa tradição das gramáticas de referência, mesmo quando delas me afasto"(p. 33).

O que percebemos com a observação das cinco gramáticas é uma continuidade alternada com uma descontinuidade aos achados da GT. As gramáticas contemporâneas ora se afastam, ora retomam o elo com a GT. O que significa que os estudos da Linguística moderna aprimoram suas ações interpretativas, acrescentando-as às lições tradicionais, em maior ou menor medida, de acordo com critérios e concepções de seus autores. 


\section{Considerações finais}

Lidar com questões de linguagem é proceder cientificamente e, para tanto, é preciso eleger certos critérios de análise. As cinco obras aqui analisadas apresentam seus critérios para um empreendimento robusto, a fim de concretizar um trabalho de pesquisa de anos. Apesar de tanto empenho, como aponta Perini (2010), nenhuma gramática oferece uma descrição completa e definitiva "porque a linguística é uma ciência viva e em pleno desenvolvimento, não um conjunto de técnicas estabelecidas há muito tempo e que só temos que aplicar" (p.22).

Realizar alguns ajustes, seja na definição do público-alvo, na seleção dos exemplos, ou na simplicidade ou complexidade da exposição dos fenômenos linguísticos, é atividade comum em qualquer obra, podendo ser realizada a cada nova edição. A insatisfação com as propostas descritivas é normal e esperada em qualquer ciência e, nos estudos da linguagem, não poderia ser diferente. Essa condição constante no fazer científico permite estarmos sempre em busca da verdade mais recente.

Para professores, estudantes da área ou leigos, é um privilégio poder contar com a variedade de propostas de estudo do português, seja como uma língua comum da lusofonia, seja como o brasileiro. Elas nos fornecem modelos, referências e perspectivas de interpretação da língua em suas diferentes realizações e, portanto, são relevantes para nossa educação linguística.

\section{Abstract}

The area of linguistic studies has important reference works published in Brazil. In this study, we selected five grammars, namely Moderna Gramática Portuguesa, Gramática de Usos do Português, Gramática Houaiss da Língua Portuguesa, Nova Gramática do Português Brasileiro e Gramática da Língua PortuguesaPadrão, with the purpose of understanding which language conception guides production of each work and, thus, to present an overview on the subject. We have chosen to organize this article into two sections. First, we analyze the introductory part in which the authors establish criteria for textual elaboration, comparing information about the planning of works (theoretical positioning, target audience, metalinguistic complexity). Next, we verify, based on the organization and content described in the grammars, the assumed approach. At the end of the analysis, we find moderate conceptions of continuous and discontinuous interpretation of the traditional grammatical description.

Keywords: language design; Portuguese approaches; Grammatical description

\section{REFERÊNCIAS}


ANJOS, Marcelo Alessandro L. dos. (2016) Gramática da Língua Portuguesa Padrão: (des)continuidades? In: FARACO, A. C. e VIEIRA, F. E. (Orgs.) Gramáticas brasileiras, com a palavra os leitores. São Paulo: Parábola.

AZEREDO, José Carlos S. de. (2010) Gramática Houaiss da língua portuguesa. São Paulo: Publifolha/IAH.

BECHARA, Evanildo C. (2015) Moderna gramática portuguesa. Rio de Janeiro: Nova Fronteira/Lucerna.

BORGES NETO, José. (2012) Gramática Tradicional e Linguística Contemporânea: Continuidade ou Ruptura? Todas as letras, São Paulo, v. 14, n. 1, p. 87-98.

CASTILHO, Ataliba T. de. (2010) Nova gramática do português brasileiro. São Paulo: Contexto.

HAUY, Amini Boaianin. (2014) Gramática da língua portuguesa padrão. São Paulo: EdUSP.

HENRIQUES, Claudio Cezar. (2009) Nomenclatura Gramatical Brasileira: 50 anos depois. São Paulo: Parábola Editorial.

LIMA, Ana. (2016) Gramática de usos do português: metalinguagem em função. In: FARACO, A. C. e VIEIRA, F. E. (Orgs.) Gramáticas brasileiras, com a palavra os leitores. São Paulo: Parábola.

NEVES, Maria Helena de M. (2011) Gramática de usos do português. São Paulo: EdUSP.

PERINI, Mário Alberto. (2010) Gramática do português brasileiro. São Paulo: Parábola. 